\title{
BIOPRODUKSI FLOROGLUSINOL OLEH JAMUR ENDOFIT COELOMYCETES AFAS-F3 YANG DIISOLASI DARI TUMBUHAN Archangelesia flava L. MERR.
}

\author{
Yuliasri Jamal, Praptiwi, Ahmad Fathoni dan Andria Agusta* \\ Laboratorium Biosains, Bidang Botani, Puslit Biologi LIPI \\ Jl Raya Bogor Km 46, Cibinong 16911. \\ E-mail: bislunatin@yahoo.com
}

\begin{abstract}
Isolation and identification of secondary metabolites of endophytic fungus associated with the plant of Archangelisia flava Merr. and antibacterial activity test were done in this study. Extraction of biomass of endophytic fungus culture and its secondary metabolites isolation were done in ethyl acetate and methanol solvent then followed by thin layer and colomn chromatography. The fractions from colomn chromatography were tested for antibacterial activity against Escherichia coli by paper disc method. The result showed that the extract composed of 9 fractions. Fraction 4th and 8th had growth inhibition zone, $8 \mathrm{~mm}$ and $10 \mathrm{~mm}$ respectively, against E.coli at the concentration of $100 \mathrm{mg} / \mathrm{ml}$. Isolation and purification process through several chromatography techniques yielded one major metabolites wich was identified as phloroglucinol by co-chromatography technique on a GC-MS machine. Phloroglucinol can produce $10 \mathrm{~mm}$ clear zone on a disc antibacterial assay against $E$. coli.
\end{abstract}

Key words: antibacterial, Arcangelisia flava, endophytic fungi, phloroglucinol

\section{PENGANTAR}

Pemanfaatan tumbuhan sebagai bahan obat telah dikenal oleh masyarakat sejak lama. Salah satu famili tumbuhan yang telah banyak dimanfaatkan sebagai bahan obat yang potensial adalah Menispermaceae. Pada famili Menispermaceae telah diketahui adanya senyawa alkaloid protoberberin yang terdiri dari berberin, jatrorrhizin, dan palmatin. Senyawa golongan alkaloid protoberberin (berberin, palmatin, jatrorrhizin) yang merupakan senyawa karakteristik dari tumbuhan famili Menispermaceae, seperti Archangelesia flava, Coscinium fenestratum, Tinospora crispa, dan lain-lainya yang secara farmakologi telah memperlihatkan aktivitas biologi dengan spektrum penyakit yang luas. Alkaloid protoberberin dilaporkan aktif sebagai antibiotika melawan bakteri Gram positif maupun bakteri Gram negatif seperti Diplococcus pneumoniae, Eschericia coli, Neisseria gonorrhoeae, Salmonella typosa, Shigela dysentriae, Staphylococcus aureus, dan lain sebagainya. Di samping itu, alkaloid protoberberin juga memperlihatkan aktivitas sebagai inhibitor pertumbuhan sel-sel Ehrlich dan Lymphoma acites tumor, serta memiliki efek sitotoksik terhadap sel HeLa dan sel KB secara in vitro. Uniknya, alkaloid protoberberin juga aktif sebagai antiplasmodium melawan Plasmodium falciparum (Mandia, 1999). Menurut Keawpradub et al. (2005) ekstrak metanol A. flava mempunyai aktivitas antioksidan dengan nilai $\mathrm{EC}_{50}$ adalah $25,7 \pm 1,7 \mu \mathrm{g} / \mathrm{ml}$, juga bersifat sitotoksik terhadap sel lestari MCF-7 (sel kanker payudara) dengan nilai $7,7 \pm 0,6 \mu \mathrm{g} / \mathrm{ml}$.

Di lain pihak telah diketahui pula bahwa di dalam jaringan sehat tumbuhan terdapat mikroba yang hidup berasosiasi dengan tumbuhan yang disebut sebagai mikroba endofit. Golongan mikroba endofit ini terutama jamur endofit, merupakan sumber yang kaya akan metabolit sekunder (Tan and Zou, 2001) aktif-biologi sehingga Owen and Hundley (2004) menyebutnya sebagai the chemical synthesizer inside plant.

Dalam laporan terdahulu kita telah melaporkan metabolit sekunder yang bersifat sebagai antibiotika dari jamur endofit yang berasosiasi dengan tumbuhan A. flava yang dikoleksi dari Kalimantan (Praptiwi et al., 2010). Pada tulisan ini akan dilaporkan metabolit utama pada salah satu jamur endofit yang berasosiasi dengan tumbuhan A. flava yang dikoleksi dari Sukabumi.

\section{BAHAN DAN METODE}

\section{Bahan Tumbuhan}

Bahan tumbuhan berupa bagian akar tumbuhan akar kuning Archangelisia flava dikoleksi dari daerah Sukabumi Jawa Barat pada bulan Maret 2008. Identifikasi jenis dilakukan di Herbarium Bogoriensis, Bidang Botani, Puslit Biologi LIPI. 


\section{Isolasi Jamur Endofit}

Bagian akar tumbuhan akar kuning dicuci kemudian dipotong lebih kurang 1-5 cm, kemudian disterilkan dengan cara merendamnya dalam alkohol $70 \%$ selama 2 menit. Selanjutnya batang tersebut direndam dalam $\mathrm{NaOCl}$ selama 5 menit dan direndam kembali dalam alkohol $70 \%$ selama 30 detik. Sampel yang telah steril dipotong dan dibelah dengan pisau steril dan diletakkan diatas medium CMMC (Corn Meal Malt Agar) yang telah mengandung kloramfenikol 0,05 mg/ml kemudian diinkubasi pada suhu kamar selama 1 minggu. Tiap koloni jamur yang tumbuh selanjutnya dipindahkan pada medium PDA(Potato Dextrose Agar) sampai diperoleh koloni tunggal.

\section{Skrining Produksi Metabolit Sekunder Jamur Endofit}

Masing-masing koloni murni jamur endofit pada media miring PDA diambil kira-kira seluas $1 \times 1 \mathrm{~cm}$ dan diinokulasi dalam $30 \mathrm{ml}$ media PDB, selanjutnya kultur tersebut diinkubasi pada suhu kamar dalam kondisi statis. Setelah 3 minggu, lalu diekstraksi dengan campuran etil asetat dan metanol (4:1) dan dianalisis dengan kromatografi lapis tipis yang menggunakan lempeng silika gel $\mathrm{GF}_{254}$ dengan eluen diklorometan : metanol : asam asetat ( $6: 1: 1$ tetes). Pola keromato Gram KLT yang terbentuk divisualisasikan dengan pemaparan sinar UV pada panjang gelombang 254 dan $365 \mathrm{~nm}$. Di samping itu dilakukan juga dengan pereaksi penampak noda $10 \%$ vanilin $/ \mathrm{H}_{2} \mathrm{SO}_{4}$ dan $1 \% \mathrm{Ce}(\mathrm{SO} 4) 2 / 10 \% \mathrm{H}_{2} \mathrm{SO}_{4}$.

\section{Scaling-up Kultivasi dan Isolasi serta Purifikasi Metabolit Sekunder Utama AFAS-F3}

Jamur endofit AFAS-F3 di kultivasi di dalam $5 \times 200$ $\mathrm{ml}$ PDB (di dalam Erlenmeyer $500 \mathrm{ml}$ ) dan diinkubasi pada suhu ruang dalam kondisi statis. Setelah 3 minggu, kultur jamur AFAS-F3 pada media PDB dan biomassanya diekstraksi $3 \times$ dengan etil asetat : metanol (4:1), lalu divortex dan dibiarkan sampai terbentuk 2 lapisan. Lapisan atas diambil, lalu dipekatkan dengan rotary evaporator. Ekstrak yang diperoleh selanjutnya dipisahkan dengan teknik kromatografi kolom menggunakan silika gel F60 (70-230 mesh) sebagai fase diam dan dielusi secara step wise dengan diklorometana-metanol (15:1 1:1). Fraksi yang keluar ditampung pada tabung reaksi kemudian diidentifikasi dengan KLT. Fraksi yang mempunyai bercak yang sama digabung menjadi 1 fraksi dan dipekatkan dengan rotary evaporator. Fraksi-fraksi yang diperoleh diamati aktivitas antibakterinya. Proses pemurnian dilakukan dengan KLT preparatif menggunakan lempeng silika gel
$\mathrm{GF}_{254}$ (Merck) dengan eluen diklorometan : metanol : asam asetat $(6 ; 1 ; 1$ tetes). Senyawa murni yang diperoleh selanjutnya dikeringkan dengan rotary evaporator pada temperatur $30^{\circ} \mathrm{C}$.

\section{Uji Antibakteri}

Stok bakteri yang telah diremajakan pada NA miring diambil 1 ose, lalu disuspensikan dalam $5 \mathrm{ml}$ Mueller Hinton Broth (MHB), selanjutnya diinkubasi dengan shaker inkubator $100 \mathrm{rpm}$ pada suhu $37^{\circ} \mathrm{C}$ selama $18 \mathrm{jam}$. Suspensi ini digunakan dalam pengujian antibakteri.

Media Mueller Hinton Agar (MHA) yang telah padat ditambahkan inokulum sebanyak $100 \mu \mathrm{l}$ kemudian diratakan dengan spreader dan diamkan selama kurang lebih 15 menit. Ekstrak pada konsentrasi $100 \mathrm{mg} / \mathrm{ml}$ diteteskan pada kertas cakram steril $(10 \mu \mathrm{l})$. Selanjutnya kertas cakram tersebut diletakkan secara aseptis di atas media yang telah diinokulasi dengan bakteri kemudian diinkubasi selama 18-24 jam pada suhu $37^{\circ} \mathrm{C}$. Zona bening yang terdapat disekitar kertas cakram merupakan zona hambat pertumbuhan dan diukur diameternya dengan jangka sorong.

\section{Identifikasi Struktur Senyawa dengan GC-MS}

Identifikasi struktur senyawa metabolit sekunder utama jamur endofit AFAS-F3 dilakukan dengan menggunakan GC-MS (Varian Saturn 2000) dengan kolom kapiler VF-17 MS (30 $\mathrm{m} \times 0,25 \mathrm{~mm})$. Gas pembawa adalah He dengan kecepatan aliran $2.0 \mathrm{ml} /$ menit. Suhu kolom diprogram dari $50^{\circ} \mathrm{C}$ sampai $250^{\circ} \mathrm{C}$ dengan dua tahap kenaikan. Pada tahap awal suhu kolom dibuat konstan $50^{\circ} \mathrm{C}$ selama 5 menit, lalu dinaikkan sampai $150^{\circ} \mathrm{C}$ dengan kecepatan kenaikan temperatur $10^{\circ} \mathrm{C} /$ menit, lalu dinaikkan kembali sampai $250^{\circ} \mathrm{C}$ dengan kecepatan kenaikan temperatur $5^{\circ} \mathrm{C} /$ menit. Kemudian pada kondisi ini dipertahankan selama 15 menit. Suhu injektor selama analisis berlangsung diprogram konstan pada suhu $230^{\circ} \mathrm{C}$. Sementara temperatur interface adalah $250^{\circ} \mathrm{C}$ dengan scan MS 50-400 (M/Z). Identifikasi metabolit utama dari kultur jamur endofit AFAS-F3 dilakukan dengan membandingan spektrum massa dari metabolit utama dengan spektrum massa autentik pada National Institute Standard of Technology (NIST) Library dan senyawa floroglusinol standar (Merck) dengan tehnik ko-kromatografi.

\section{HASIL}

Dari bagian akar tumbuhan Archangelisia flava Merr. berhasil diisolasi tiga jenis jamur endofit yakni AFASF1, AFAS-F2, dan AFAS-F3. Hasil skrining produksi 


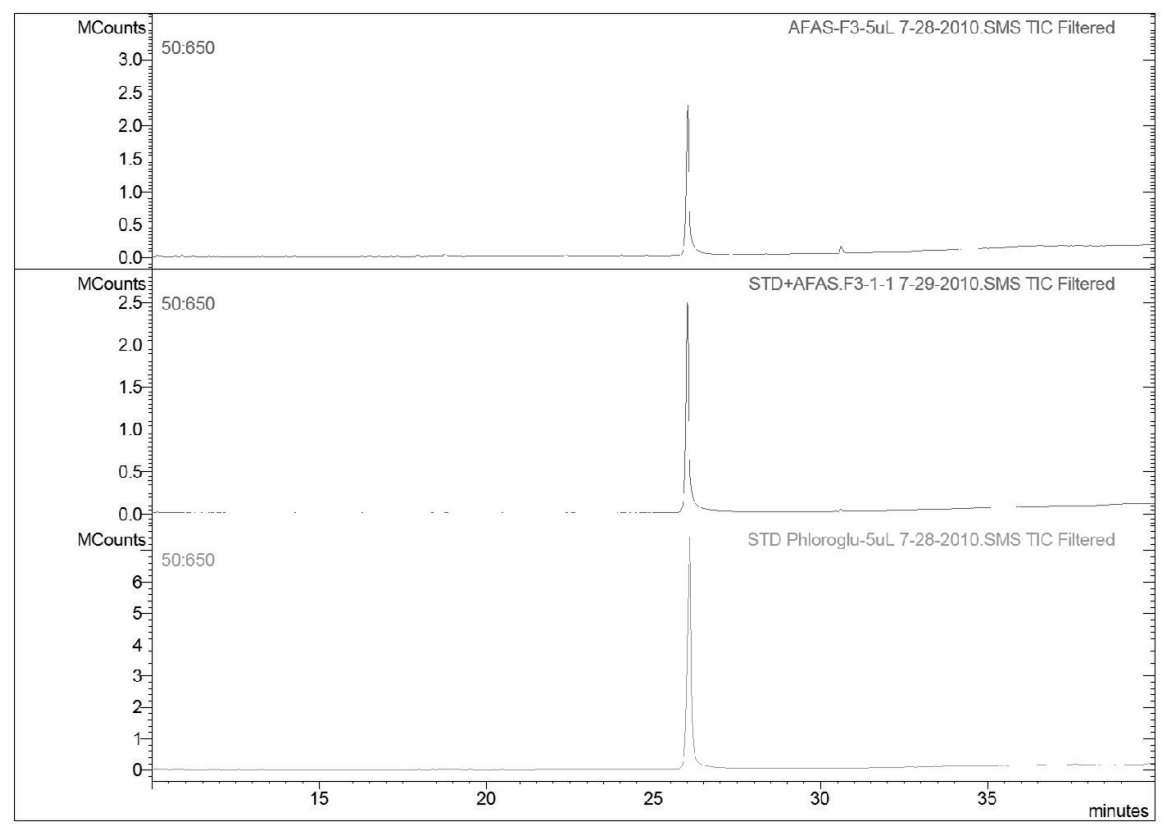

Gambar 1. Profil kromatoGram GC-MS komponen kimia utama dari kultur AFAS-F3 (atas), campuran komponen kimia utama kultur AFAS-F3 dengan penambahan floroglusinol standar (tengah) dan standar floroglusinol (bawah).

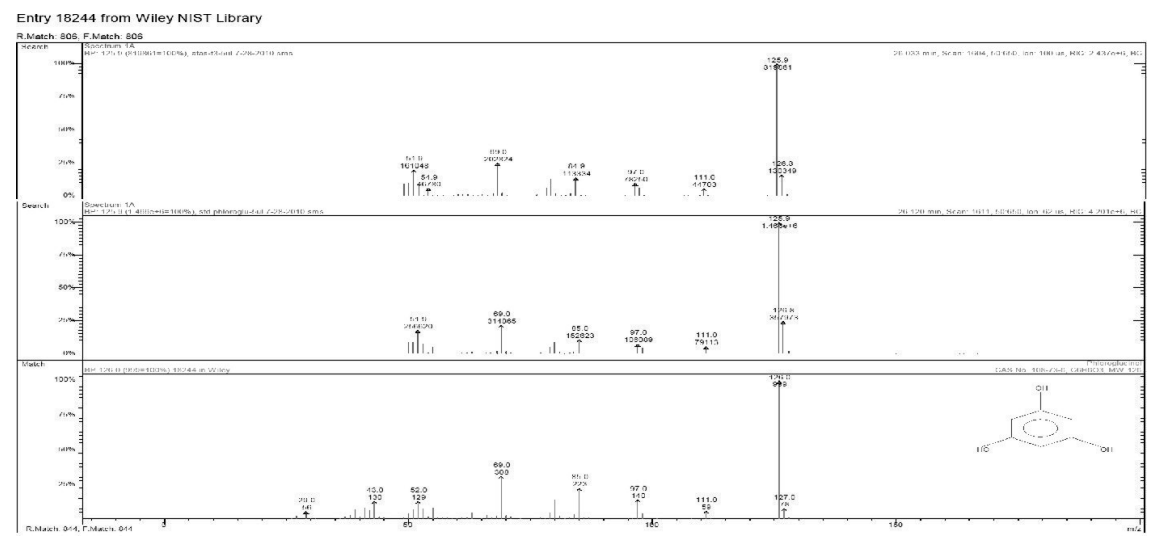

Gambar 2. Spektrum Massa senyawa kimia utama pada kultur jamur endofit AFAS-F3 (atas), standar floroglusinol (tengah) dan floroglusinol pada NIST Library (bawah).

metabolit sekunder yang diikuti oleh analisis ekstrak etil asetat-metanol kultur ketiga jamur tersebut memperlihatkan bahwa jamur endofit AFAS-F3 dapat memproduksi satu metabolit sekunder utama yang ditandai dengan terbentuknya spot tunggal pada kromatogram KLT nya (data tidak ditampilkan). Berdasarkan hasil ini, maka pada tahap penelitian selanjutnya difokuskan kepada jamur endofit AFAS-F3.

\section{PEMBAHASAN}

Floroglusinol (1,3,5-trihidroksibenzena) dan turunannya telah digunakan secara luas pada produk komersial.
Floroglusinol dan turunannya seperti trimetilfloroglusinol, digunakan sebagai bahan obat sebagai antispasmodik. Menurut Lafon (2009), berdasarkan hasil uji pre-klinik pada hewan coba menunjukkan bahwa floroglusinol berfungsi sebagai antispasmodik non atropin dan dapat diinjeksikan secara intravena maupun intramuscular. Selanjutnya Lafon (2009) juga menyatakan bahwa cara bekerja floroglusinol adalah dengan cara menghambat enzim COMT (CatecholO-Methyl Transferase). Lee et al. (2003) menyimpulkan bahwa dua turunan floroglusinol yang diisolasi dari rizhom D. crassirhizoma yaitu flavaspidic acids $\mathrm{PB}$ (1) and $\mathrm{AB}$ (2), menunjukkan aktivitas antioksidan yang potensial terhadap 
penghambatan peroksidasi lipid dengan $\mathrm{IC}_{50} 12,9$ and $13,1 \mu \mathrm{M}$ berturut-turut yang mungkin disebabkan adanya pengkhelatan terhadap Fe. $\mathrm{IC}_{50} \alpha$-tokoferol $(15,6 \mu \mathrm{M})$ dan butylated hidroksi anisole (BHA) 10,8 $\mu \mathrm{M}$, Kedua turunan floroglusinol tersebut menunjukkan aktivitas antioksidan sedang terhadap radikal bebas DPPH $\left(\mathrm{IC}_{50} ; 71,7 ; 76,3 \mu \mathrm{M}\right)$ dan superoksida $\left(\mathrm{IC}_{50} ; 58,6 ; 64,4 \mu \mathrm{M}\right)$.

Di samping itu floroglusinol juga digunakan secara luas sebagai bahan dasar atau intermediet dalam sintesis bahan obat, mikrobisida atau dalam sintesis organik. Floroglusinol juga digunakan sebagai pewarna untuk sampel yang mengandung tanin pada analisis dengan mikroskop, dan juga digunakan sebagai pewarna pada industri kulit, tekstil dan pewarna rambut. Senyawa ini juga digunakan dalam pembuatan bahan peledak yang stabil terhadap temperatur dan benturan seperti 1,3,4-triamino-2,4,6-trinitrobenzena (TATB, Frost, 2007).

Saat ini, senyawa floroglusinol telah diproduksi melalui sintesis kimia dengan kapasitas produksi 140 ton/tahun (Zao, 2008). Dengan ditemukannya jamur endofit AFAS-F3 yang dapat memproduksi floroglusinol secara in vivo telah membuka peluang baru untuk proses produksi floroglusinol yang bebas dari limbah bahan kimia berbahaya dan lebih bersahabat dengan lingkungan atau lebih dikenal dengan istilah Green Chemistry.

Kesimpulan dari penelitian ini adalah dari akar tumbuhan akar kuning (Archangelisia flava) yang diperoleh dari Sukabumi dapat diisolasi 3 jenis isolat jamur endofit berbentuk filamen. Salah satunya, yaitu jamur endofit AFASF3 yang berasosiasi dengan tumbuhan $A$. flava memiliki kemampuan untuk memproduksi floroglusinol di dalam medium PDB dengan kapasitas produksi 14,9 mg/L.

\section{UCAPAN TERIMAKASIH}

Diucapkan terimakasih kepada Arif Hidayat SSi., yang telah mengoleksi dan mengidentifikasi jenis tumbuhan
A. flava. Disampaikan juga terimakasih kepada Hertina, Andi Saptaji Kamal dan Tika Lestari atas asistensinya di laboratorium.

\section{KEPUSTAKAAN}

Frost JW, 2007. Biosynthesis of Phloroglucinol and Preparation of 1,3-dihydroxybenzene therefrom. United States Patent Application 20070178571.

Keawpradub N, Dejadisai S, and Yuenyongsawad S, 2005. Antioxidant and Cytotoxic Activities of Thai Medicinal Plants Named Khaminkhruea: Arcangelisiaflava, Coscinium blumeanum, and Fibraurea tinctoria. Songklanaklarin J. Sci. Technology, 27 (suppl. 2): 455-467. Diakses: 2 November 2010.

Lafon L, 1962. Pharmaceutical Compositions Containing Phloroglucinol. Patent GB904955.

Lee Sang-Myung, Na Min-Kyun, An Ren-Bo, Min Byung-Sun, Lee Hyeong-Kyu, 2003. Antioxidant Activity of Two Phloroglucinol Derivatives from Dryopteris Crassirhizoma. Biol. Pharm. Bull., 26(9): 1354-1356.

Mandia EH, CE Ridsdale, SFAJ Horsten and AM Aguinaldo, 1999, Arcangelesia flava (L.) Merr., in Plant Resources of SouthEast Asia 12; Medicinal and Poisonous Palnts 1, Eds.: L.S. de Padua, N Bunyaprapatsara, and RHJ Lemmens, Prosea, Leiden, p. 129-132.

Owen NL and N Hundley, 2004. Endophytes-the Chemical Synthesizers Inside Plants. Science Progress, 87(2), 79-99.

Pratiwi, Y. Jamal, A. Fathoni and A. Agusta, 2010. Antimicrobial metabolite from the culture of endophytic fungus AFK-8 isolated from kayu kuning (Archangelisia flava (L.) Merr. Paper presented on International Seminar "Biotechnology for enhancement the tropical biodiversity”, Universitas Pajajaran, 18-20 October 2010.

Tan RX and WX Zou, 2001. Endophytes: A Rich Source of Functional Metabolites. Nat. Prod. Rep., 18: 448-459.

Zao H, 2008. Microbial Synthesis of Phloroglucinol and Xylitol. J. Biotechnol., 136S: S402-S459.

Reviewer: Tim Reviewer 